\title{
Seepage Investigation of Embankment Dams using Numerical Modelling of Temperature Field
}

\author{
S. Yousefi ${ }^{1 *}$, A. Noorzad ${ }^{2}$, M. Ghaemian ${ }^{3}$ and S. Kharaghani ${ }^{2}$ \\ 'Ph.D. Candidate, Department of Civil Engineering, Science and Research \\ Branch, Islamic Azad University, Tehran, Iran; yous1383@hotmail.com \\ ${ }^{2}$ Assistant Professor, Faculty of Water and Environmental Engineering, \\ Department of Civil Engineering, Shahid Abbaspour, Power and Water University of \\ Technology,Tehran, Iran; geonek@gmail.com, kharaghanis@yahoo.com \\ ${ }^{3}$ Associate Professor, Department of Civil Engineering, Sharif University of \\ Technology, Tehran, Iran; mghaemian@sharif.edu
}

\begin{abstract}
Leakage in embankment dam by applying seepage and thermal numerical simulations are studied in this paper. Unpredicted seepage in earthen dams is known as the main cause of damage in most cases. Determination of seepage flow quantity and prediction of dam leakage is very important. Temperature variation in dam body can be simulated to estimate the water velocity in soil layers. While moving through dam body, seepage flow carries all physical specifications of reservoir water, including its temperature. Mass and energy balance equations are discretized for modeling flow and temperature fields. The finite element method along with a mathematical model has been utilized to discretize and solve the governing equations in saturated and unsaturated zones. Shamil embankment dam located in South of Iran is considered as a case study to investigate the proposed model. To evaluate the condition of dam, different cases of soil materials with different permeability coefficients are analyzed and compared with measured data. Numerical results of seepage and temperature modeling are compared and discussed. The obtained results indicate that inspecting temperature data can magnify the effect of leakage more clearly than investigating piezometric head data.
\end{abstract}

Keywords: Seepage Flow, Thermal Simulation, Embankment Dam, Finite Element Analysis, Shamil Dam, Leakage.

\section{Introduction}

Embankment dam safety program usually includes surveillance systems to address seepage flow control and leakage detection. Leakage quantity is often referred as one of the key parameters for evaluating dam safety. Different instruments are installed in dam body for collecting seepage flow parameters, in order to measure seepage rates and to be able to observe the possible presence of transported materials. The spatial resolution of these instruments is often not refined enough to detect small and local seepage characteristics. This seems to be one of the main reasons that most internal erosion incidents have been detected by visual inspections and not by any monitoring systems [3]. Hence, there is a need for new and improved seepage det-ection and monitoring techniques.

Temperature value is very easy to measure and can give useful information about the presence of anomalous flows being transported from different regions of a dam [1]. Measurement of temperature in dams for leakage detection was started in Germany in the late 1950's [6]. Extensive research has also been performed, specially in Germany and Sweden, from 1950' for three decades [7].

The seasonal temperature variations that occur in all surface water (such as lakes, reservoirs and rivers), causes a seasonal variation of the seepage flow that passes

*Corresponding author:

S. Yousefi (yous1383@hotmail.com) 
through a dam. This phenomenon is developed to be the fundamental of seepage monitoring method in dams, described by Kappelmayer in 1957 and Johansson et al [4]. The magnitude of this seasonal temperature variation can be measured in a dam and is correlated to the seepage flow through the dam.

In order to monitor the leakages over long periods and distances, the distributed temperature sensors, based on optical fibers, provide an efficient solution. These instruments are capable of giving a global view as well as a detailed local view of the inspected site [2].

Seepage monitoring by applying temperature tracking method is nowadays being recognized as the most effective way to detect seepage flow variations with high sensitivity along the dam [9]. This paper provides the application of seepage flow simulation and temperature transmission modeling to evaluate the piping characteristics. Comparing different options of leakage can reveal efficiency of application of both flow and thermal simulation for quantifying dam measured data.

\section{Seepage Flow and Temperature Variation in Dams}

Air temperature and dam reservoir water temperature affects the temperature within embankment dam. Hence, temperature varies seasonally and creates temperature waves that propagate through the dam. Generally, the seepage flow is small in embankment dams and the seasonal temperature variation in the dam depends essentially on the air temperature at the surface. The influence from the air is however less than $1^{\circ} \mathrm{C}$ for depths in the dam body that exceed $10 \mathrm{~m}$. At such depths, the influence from the air is therefore negligible. At high seepage rates, the temperature variation of the water in the upstream reservoir completely determines the temperature inside the dam. Then, the seasonal temperature variation in the dam is directly proportional to the seepage rate.

It can be said that a constant temperature in downstream of dam core is a sign of a small seepage, while large seasonal variations may be a sign of significant seepage. Seasonal variation of dam temperature increase while rising seepage flow. This variation is dependent on seepage flow, the seasonal variation at the inflow boundary and the distance from the boundary to the measuring point. Thermo hydraulic behaviour of an embankment dam is generally complex. It can be studied as different basic thermal processes including heat conduction, advection and dispersion. The problem is further complicated by the variation in material properties of the dam, and the different conditions in the saturated and unsaturated parts of the dam in order to analyze the problem. Certain assumptions have generally to be made. The general problem can, however, be studied using coupled mass flow and energy transport models. Concentration equations of mass and energy can be applied to simulate seepage flow and heat transportation through porous media.

\subsection{Seepage Differential Equation}

The mass conservation equation in a porous media can be expressed as:

$$
\frac{\partial\left(\rho_{f} n\right)}{\partial t}+\frac{\partial}{\partial X_{i}}\left(\rho_{f} q_{i}\right)=0
$$

where $\rho_{f}=$ the density of the fluid, $\left(\mathrm{kg} / \mathrm{m}^{3}\right) ; n=$ porosity coefficient; $X_{i}=$ distance; $q_{i}=$ leakage flow (Darcy flow), $\left(\mathrm{m} / \mathrm{s}\right.$ or $\mathrm{m}^{3}$ per $\mathrm{m}^{2}$ and $\left.\mathrm{s}\right) ; t=$ the time.

General form of Darcy's law can describes the velocity of seepage water by giving:

$$
q_{i}=-\frac{k_{i j}}{\mu}\left(\frac{\partial p}{\partial X_{i}}+\rho_{f} g_{i}\right)
$$

in which $k_{i j}=$ permeability; $\mu=$ dynamic viscosity; $p=$ pressure; $g_{i}=$ gravity.

By combining Equations (1) and (2), the equation of motion for the leakage water flow can be obtained:

$$
\frac{\partial\left(\rho_{f} n\right)}{\partial t}+\frac{\partial}{\partial x_{i}}\left(k_{i j} \frac{\partial p}{\partial x_{i}}+\rho_{f} k_{i j} g_{i}\right)=0
$$

The above equation describes the leakage water flow induced by variation in pressure (or piezometric head) and by variation in density of the water.

\subsection{Temperature Variation Equation}

The energy flux consists of heat conduction in the solid phase and heat transportation in the liquid phase in an earth-fill dam. Energy flux in the water (liquid phase) includes heat advection with the average leakage water flow, and dispersion due to variability in the leakage water flow velocities. The energy (temperature) balance equation can 
be expressed in the form of general advection-dispersion equation [5]:

$$
c_{0} \frac{\partial T}{\partial t}=\frac{\partial}{\partial x_{i}}\left(\lambda_{0} \frac{\partial T}{\partial x_{i}}-c_{w} T q_{i}-Q_{i}^{d i s p}\right)
$$

where $c_{0}=$ volumetric heat capacity of soil, $\left(\mathrm{J} / \mathrm{m}^{2} \mathrm{k}\right)$; $c_{w}=$ volumetric heat capacity of water, $\left(\mathrm{J} / \mathrm{m}^{2} \mathrm{k}\right) ; Q_{i}^{\text {disp }}=\mathrm{en}-$ ergy flux due to mechanical and thermal dispersion, $\left(\mathrm{J} / \mathrm{m}^{2} \mathrm{~s}\right) ; q_{\mathrm{i}}=$ leakage flow (Darcy flow), $\left(\mathrm{m} / \mathrm{s}\right.$ or $\mathrm{m}^{3}$ per $\mathrm{m}^{2}$ and $\mathrm{s}) ; T=$ temperature, $\left({ }^{0} \mathrm{c}\right) ; t=$ time, $(\mathrm{s}) ; x_{i}=$ coordinate; $\lambda_{0}=$ thermal conductivity of soil.

Equation (4) describes the time variation of energy based on advection terms (related to leakage flux), diffusive terms (related to soil thermal conductivity) and dispersive terms (related to soil thermal dispersion).

\section{Case Study}

Shamil embankment dam located in the south of Iran has been considered as the case study to investigate the proposed model. The height of the dam is $32.2 \mathrm{~m}$ with a reservoir volume of $115 \mathrm{MCM}$. A total of eight different soil types were taken to simulate base, core, shell, drainage and filter of Shamil dam.

\subsection{Dam Specifications}

Shamil earthen dam is constructed as zoned rock fill embankment dam with vertical central core. Dam crest width is $8 \mathrm{~m}$ and length is $1200 \mathrm{~m}$.

The body of dam is rock-fill embankment with a slightly inclined central core made of fine clay. During last 1.5 years, an annual water level fluctuation in reservoir was about $18 \mathrm{~m}$ $(+112$ to $+130.0 \mathrm{~m})$, which is half the height of the dam. The foundation material of dam is conglomerate (permeability factor in $\mathrm{m} / \mathrm{s}: \mathrm{K}=1 \times 10^{-5}$ ). Dam body materials consists different layers, including: dam shell $\left(\mathrm{K}=2.3 \times 10^{-5}\right)$, core $\left(\mathrm{K}=8.3 \times 10^{-9}\right)$, filter $\left(\mathrm{K}=2.5 \times 10^{-8}\right)$, cutoff $(\mathrm{K})[8]$.

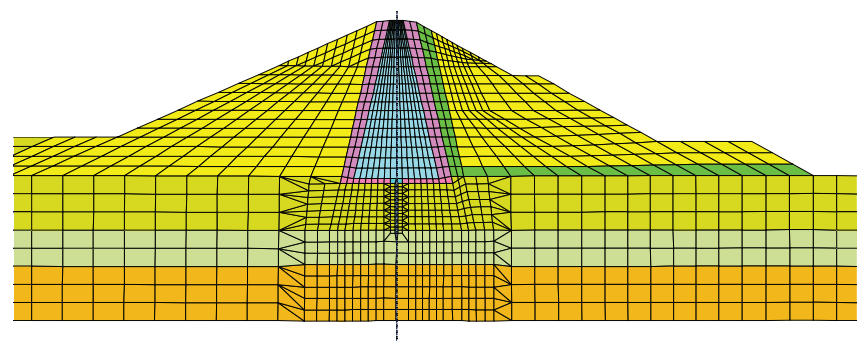

Figure 1. Computational domain of Shamil dam.

\subsection{Computational Domain}

While dam designation, total of 21 different cross sections are studied. Instrumentation of Shamil dam are installed on sections number 10,14,19, and 21. Section number 14 is the largest section of the dam, located almost on the middle of the river and is selected for seepage studies in this paper. In section 14, the bottom layer of foundation is about $76 \mathrm{~m}$ and the top layer of foundation is $110 \mathrm{~m}$, where bottom of core is constructed. Also, dam crest is at $142.5 \mathrm{~m}$. By considering dam cross-section, which has 203 $\mathrm{m}$ length at the riverbed level, total length of foundation is considered to be $250 \mathrm{~m}$.

Total number of elements in the cross section is 1433 and total number of nodes is 1451 . In the horizontal direction, computational domain is discretized into 56 elements and in the vertical direction into 48 elements. Minimum dimension of elements is about $0.5^{*} 0.5 \mathrm{~m}$ closed to cutoff wall and the maximum size of elements increase to $7.5^{*} 4 \mathrm{~m}$ at the upstream side of dam foundation. (Figure 1)

\subsection{Dam Reservoir Conditions}

Shamil dam construction was finalized and impounding was started from 2010. Riverbed at dam axis was $112 \mathrm{~m}$

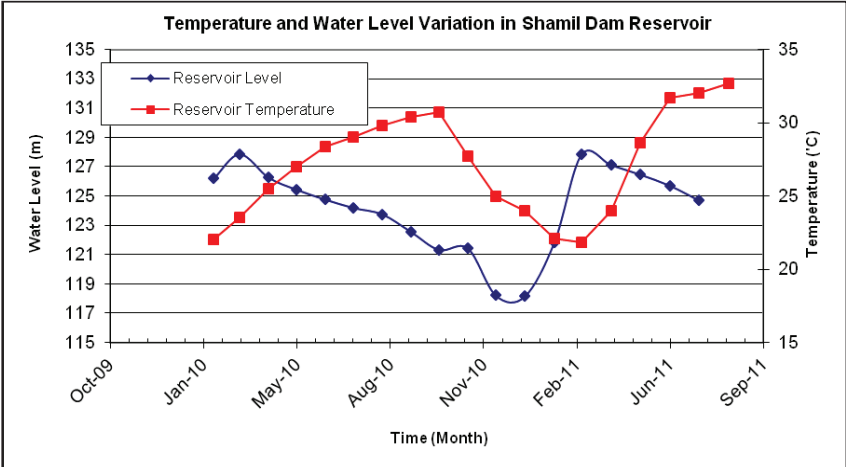

Figure 2. Water level and temperature variation in the reservoir of Shamil dam.

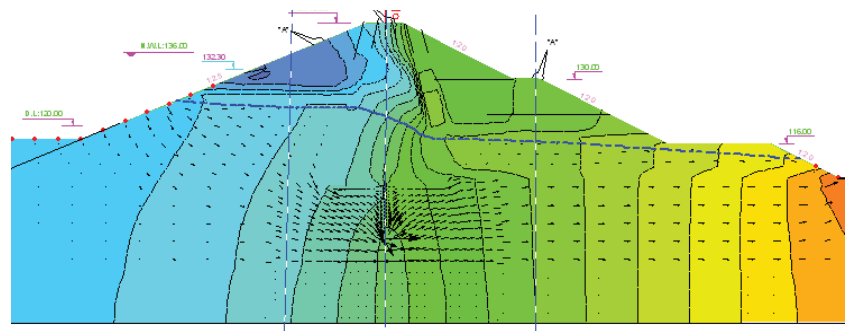

Figure 3. Numerical results of flow pattern in section 14 in Aug. 2011 (the upstream and downstream parts of foundation is not shown in the figure). 


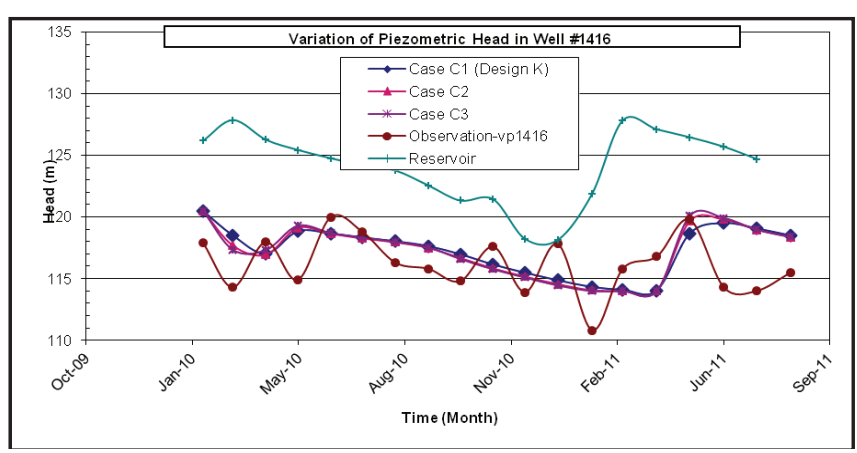

Figure 4. Monthly variation of piezometric head in Piezometer 1416 for all options.

before impoundment and increased to $118 \mathrm{~m}$ due to huge sedimentation, then and remained constant for about two years (during the studying period). Within the last 1.5 years, water level in dam reservoir was varying mostly between 118 and 129 m, shown in Figure 2. These variations can be considered as upstream boundary conditions for unsteady seepage simulation. Water temperature in dam reservoir was also varying within 19 to 35 degrees centigrade as illustrated in Figure 2. The simulation of temperature is done using unsteady boundary conditions.

\section{Seepage Simulation}

Water level and temperature-measured data in dam reservoir that are shown in Figure 2 were applied as the upstream boundary condition for seepage and temperature numerical modeling. At the downstream face, water level was measured to be on the riverbed at $112 \mathrm{~m}$. Figure 3 shows the results of numerical simulation of seepage flow based on design data. The velocity varies from 0.3 to 0.5 $\mathrm{m}$ /day in the downstream drain. By investigating velocity values in different zones, the minimum transport time of a water drop from upstream towards downstream is obtained about 540 days.

Measured data show that seepage flow is more than its predicted value in the design document. Hence, different computational options were considered for unsteady seepage modelling to estimate the real constructed conditions of the dam. In each option, it was considered that shell and foundation permeability factor is more than design data and are set as described in Table 1. Other technical data are considered the same as design data. In option $\mathrm{C} 1$, permeability value is the same as design data, reported in the documents. Variations of piezometric level in wall number 14 are drown

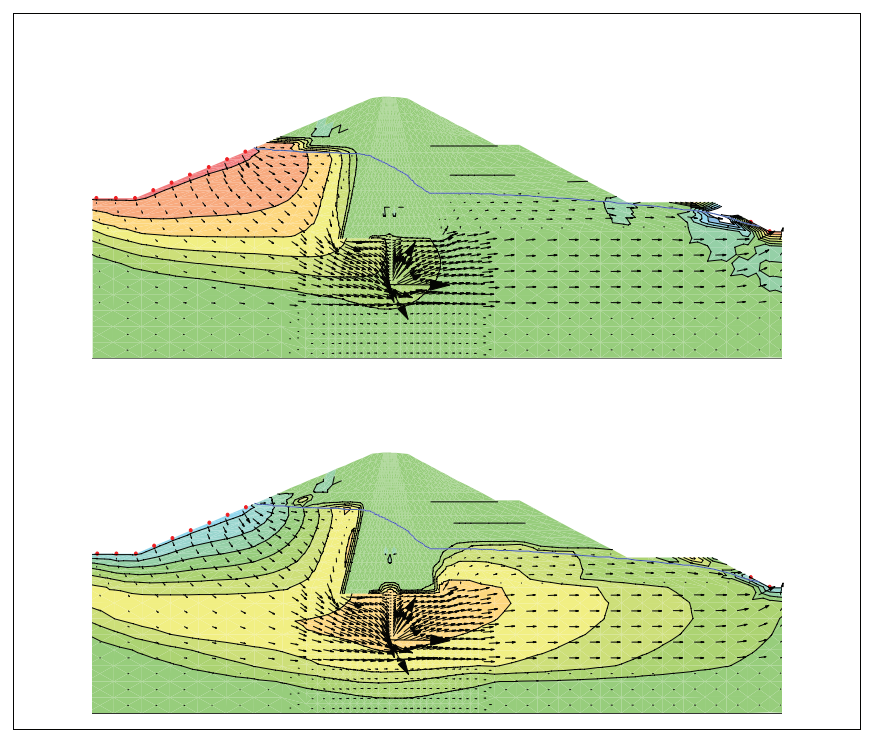

Figure 5. Simulated flow pattern and temperature counters in section 14 (a) Aug. 2010 (b) Feb. 2011.

Table 1. Permeability values of shell in different options

\begin{tabular}{cccc}
\hline Option & $\mathrm{C} 1$ & $\mathrm{C} 2$ & $\mathrm{C} 3$ \\
\hline Permeability $(\mathrm{m} / \mathrm{s})$ & $2.3 \times 10^{-5}$ & $6 \times 10^{-5}$ & $2 \times 10^{-4}$ \\
\hline
\end{tabular}

against measured values in Figure 4. Not much difference can be seen in computational results of several options, and hence, no especial conclusion can be derived.

Hence, one may argue that there are no much differences between simulated piezometric levels in all 3 options. In the other words, variation of piezometric heads of seepage modeling seems to be not enough for judgment between different seepage systems.

\section{Temperature Simulation}

Average velocity of seepage flow in the upstream shell is about $0.3 \mathrm{~m} /$ day, while the velocity increases around the cutoff mostly up to $1 \mathrm{~m} /$ day. As mentioned before, Measurement shows that average of minimum and maximum weather temperature during the last 30 years in Shamil dam region was between 19 and $35^{\circ} \mathrm{C}$. Since the maximum water depth in dam reservoir is less than $10 \mathrm{~m}$, water temperature in dam reservoir is generally equal to the weather temperature and no vertical gradient of temperature is seen. So, the reservoir temperature variation that is shown in Figure 3 can be applied as boundary conditions for all boundary elements in the upstream side of dam. The seepage flow which moves through earth fill dam keeps 
these temporal variation and almost the same variation behavior can be seen in the elements located on the upstream side of dam core. If there is a crack within the core, variation of water temperature after the core is generally the same as reservoir water temperature variation.

Based on the seepage analysis, temperature distribution in dam was simulated for a one and half years period. Predicted velocity profiles and temperature distributions after 6 and 12 months are shown in Figure 6. Differences between temperature values in same locations in different times can be clearly seen in upstream and downstream of the dam. Temperature varies very small in the down stream shell if no crack is considered in dam core. In the upstream shell, more variation in temperature values can be seen.

\section{Discussion}

To evaluate the temperature behavior of the dam, three described options were considered. Figure 6 illustrates the variation of temperature in node 1062 near Piezometer 1416 in the downstream of the core. Variation of temperature of that node is drawn for all options against measured data of Piezometer 1416 and dam reservoir. It is obviously seen that results of option C2 seems to be more closed to the measured data than other options. Hence, one may say that the real hydraulic permeability of dam body is almost the same as option C2. Hence, it may be said that seepage in this cross section of dam seems to be mainly due to higher values of hydraulic permeability of dam shell

\section{Conclusions}

Shamil dam, which is a newly constructed earth fill dam, is studied in this paper to find seepage effect variation on piezometric head and temperature field within dam body. The studying period was 1.5 years started from Feb. 2010. Seepage flow and temperature variation in the dam and its foundation were simulated by applying a finite element model with triangular and quadrilateral elements. Unsteady boundary conditions were set for seepage and temperature modeling.

Different options were considered for numerical modeling to find real conditions of constructed dam, similar to back analysis schemes. Comparison between measured piezometric head and seepage model results did not lead to any especial conclusion. However, comparing observed temperature values and thermal model results illustrated some clear differences between results of several options. These differences helped to find the real constructed conditions. It was shown that hydraulic permeability coefficient of dam shells are about three times of those were considered in design documents. It can then be said, as a general conclusion, that in a backward analysis study of earth fill dam seepage, temperature variation investigation seems to be more efficient than piezometric head variation inspection.

\section{References}

1. Aufleger M, Goltz M et al. (2008). Optimization of fiberoptic heat-up cables for leakage detection and flow velocity measurements in embankment dams, ICOLD $76^{\text {th }}$ ANNUAL MEETING, Symposium: Operation, Rehabilitation and Up-grading of Dams, Sofia, Bulgaria.

2. Cunat P, Beck Y L et al. (2009). Surveillance of dyke ageing, Proceedings of the $2^{\text {nd }}$ Internationnal Conference on Long Term Behaviour of Dams, Graz, Austria, 4.

3. Johansson S (1997). Seepage monitoring in embankment dams, Doctoral Thesis, Royal Institute of Technology, Stockholm, Sweden.

4. Johansson S (1991). Localization and quantification of water leakage in ageing embankment dams by regular temperature measurements, Proceedings ICOLD $17^{\text {th }}$ Congress, Q65, R54, Vienna, Austria.

5. Johansson S, and Dahlin T (1998). Seepage monitoring in hollby embankment dam by continuous resistivity measurements, Proceedings of $8^{\text {th }}$ Congress of the International Ass. of Eng. Geology and the Environment, Vancouver, Balkema, Rotterdam, 95-102.

6. Kappelmeyer O (1957). The use of near surface temperature measurements for discovering anomalies due to causes at depths, Geophysical Prospecting, vol 3, 239-258.

7. Merkler G P, Blinde A et al. (1985). Field investigations for the assessment of permeability and identification of leakage in dams and dam foundations, Proceedings ICOLD $15^{\text {th }}$ Congress, Q58, R7, Lausanne, Switzerland.

8. Moshanir Company (2007). Shamil Dam Technical Report.

9. Noorzad A, Taghavi A et al. (2008). Detection of internal erosion in embankment dams using temperature measurements, The $4^{\text {th }}$ National Conference on Civil Engineering, University of Tehran. 